OPEN ACCESS

Edited by: Izak Faiena,

Columbia University, United States

Reviewed by: Sebastien Hotte, McMaster University, Canada Takeshi Yuasa, Japanese Foundation For Cancer Research, Japan

*Correspondence: Urban Emmenegger urban.emmenegger@sunnybrook.ca

Specialty section: This article was submitted to Genitourinary Oncology, a section of the journal

Frontiers in Oncology

Received: 25 January 2021 Accepted: 07 April 2021 Published: 07 May 2021

Citation:

Briones J, Khan M, Sidhu AK, Zhang L, Smoragiewicz $M$ and Emmenegger U (2021) Population-

Based Study of Docetaxel or

Abiraterone Effectiveness and Predictive Markers of Progression Free Survival in Metastatic CastrationSensitive Prostate Cancer.

Front. Oncol. 11:658331. doi: 10.3389/fonc.2021.658331

\section{Population-Based Study of Docetaxel or Abiraterone Effectiveness and Predictive Markers of Progression Free Survival in Metastatic Castration-Sensitive Prostate Cancer}

\author{
Juan Briones ${ }^{1}$, Maira Khan ${ }^{1}$, Amanjot K. Sidhu ${ }^{1}$, Liying Zhang ${ }^{1}$, \\ Martin Smoragiewicz ${ }^{1,2}$ and Urban Emmenegger ${ }^{1,2,3,4 *}$
}

${ }^{1}$ Division of Medical Oncology, Odette Cancer Centre, Sunnybrook Health Sciences Centre, Toronto, ON, Canada, 2 Department of Medicine, University of Toronto, Toronto, ON, Canada, ${ }^{3}$ Biological Sciences Research Platform, Sunnybrook Research Institute, Sunnybrook Health Sciences Centre, University of Toronto, Toronto, ON, Canada, ${ }^{4}$ Institute of Medical Science, University of Toronto, Toronto, ON, Canada

Background: Both Docetaxel (DOC) and Abiraterone (ABI) improve the survival of men with metastatic, castration sensitive prostate cancer (mCSPC). However, the outcome among mCSPC patients is highly variable, while there is a lack of predictive markers of therapeutic benefit. Furthermore, there is limited data on the comparative real-world effectiveness of adding DOC or ABI to androgen deprivation therapy (ADT).

Methods: We conducted a retrospective analysis of $121 \mathrm{mCSPC}$ patients treated at Odette Cancer Centre (Toronto, ON, Canada) between Dec 2014 and Mar 2021 (DOC n = $79, A B I n=42)$. The primary endpoint studied was progression free survival (PFS), defined as the interval from start of ADT to either (i) biochemical, radiological, or symptomatic progression, (ii) start of first-line systemic therapy for castration-resistant prostate cancer (CRPC), or (iii) death, whichever occurred first. To identify independent predictive factors for PFS in the entire cohort, a Cox proportional hazard model (stepwise selection) was applied. Overall survival (OS) was among secondary endpoints.

Results: After a median follow-up of 39.6 and 25.1 months in the DOC and $\mathrm{ABI}$ cohorts, respectively, $79.7 \%$ of men in the DOC and $40.5 \%$ in the $\mathrm{ABI}$ group experienced a progression event. PFS favored the ABI cohort ( $p=0.0038$, log-rank test), with $78.0 \%$ (95\% Cl $66.4-91.8 \%)$ of $\mathrm{ABI}$ versus $67.1 \%$ (57.5-78.3\%) of DOC patients being free of progression at 12 months. In univariate analysis superior PFS was significantly related to older age at diagnosis of mCSPC, metachronous metastatic presentation, low-volume (CHAARTED), and low-risk (LATITUDE) disease, $\geq 90 \%$ PSA decrease at 3 months (PSA90), and PSA nadir $\leq 0.2$ at 6 months. Age ( $H R=0.955)$, PSA90 $(H R=0.462)$, and LATITUDE risk stratification $(H R=1.965)$ remained significantly associated with PFS in multivariable analysis. OS at 12 months was 98.7\% (96.3-100\%) and 92.7\% (85.0$100 \%)$ in the $\mathrm{DOC}$ and $\mathrm{ABI}$ groups $(\mathrm{p}=0.97)$, respectively. 
Conclusions: In this real-world group of men undergoing treatment intensification with DOC or ABI for mCSPC, we did not find a significant difference in OS, but PFS was favoring $\mathrm{ABI}$. Age at diagnosis of mCSPC, PSA90 at 3 months and LATITUDE risk classification are predictive factors of PFS in men with mCSPC.

Keywords: metastatic castration sensitive prostate cancer (mCSPC), docetaxel (DOC), abiraterone (AA), retrospective analysis, real-world effectiveness

\section{INTRODUCTION}

In developing and developed countries, the age-adjusted incidence of prostate cancer has risen with time (1). Currently, between 4 and $8 \%$ of North American men diagnosed with prostate cancer present with de novo metastatic disease (2), and approximately $10-15 \%$ develop distant metastases after local therapy with curative intent (3). Hence, there is a significant number of prostate cancer patients who ultimately will die of metastatic disease.

The contemporary standard of care for metastatic castrationsensitive prostate cancer (mCSPC) comprises androgen deprivation therapy (ADT) combined with either second generation androgen receptor signaling inhibitors (ARSIs) such as Abiraterone (ABI) $(4,5)$, Enzalutamide $(6,7)$ or Apalutamide (8), or with Docetaxel (DOC) chemotherapy (9-11). Moreover, local radiotherapy prolongs overall survival (OS) in low volume mCSPC $(12,13)$. Numerically, all of these interventions improved median overall survival (OS) in a clinically meaningful way compared to ADT alone with hazard ratios (HRs) between 0.61 and 0.88 (14). With the availability of such a broad therapeutic arsenal consisting of agents with different toxicity profiles, clinicians can choose the most suitable treatment option depending on associated comorbidities and burden as well as distribution of disease $(15,16)$.

Nonetheless, the rapid therapeutic advances over the last few years have also created challenges. First of all, there is no definite data on the comparative efficacy of the varied treatment modalities. While an opportunistic comparison of men recruited simultaneously for the $\mathrm{ADT}+\mathrm{ABI}$ and $\mathrm{ADT}+\mathrm{DOC}$ arms of the STAMPEDE trial (arms $G$ and $C$, respectively) suggests a similar OS benefit, ARSIs appear to be the preferred treatment option in meta-analyses compared to DOC when applying surface under the cumulative ranking analysis (1719). On the other hand, it is worth noting that DOC is more costeffective than ABI (20-22). Secondly, there are no validated predictive (bio)markers of response to ARSIs or DOC (23). Thirdly, the clinical studies differed with respect to the eligibility criteria used, resulting in study cohorts with varying risk profiles, be it related to high versus low volume disease as defined in the CHAARTED study, high risk disease as outlined in the LATITUDE trial, or recurrent versus de novo $\operatorname{mCSPC}(4,9$, 24). As for the CHAARTED high volume and LATITUDE high risk definitions, they are in excellent but not perfect agreement, and both predict worse outcome (25-27). Finally, numerous prostate-specific antigen (PSA) based response parameters are associated with oncological outcome [e.g., absolute PSA nadir of $\leq 0.2 \mathrm{ng} / \mathrm{ml}, \geq 50$ or $\geq 90 \%$ PSA response (PSA50 and PSA90, respectively), and median time to PSA nadir], but they are not helpful for the initial treatment decision between DOC and ARSIs (28-30).

Based on the above, we decided to study the performance of $\mathrm{ABI}$ and DOC under real-world conditions when added to ADT for the treatment of $\mathrm{mCSPC}$ to compare the oncological activity of these drugs and to identify predictive markers of response.

\section{PATIENTS AND METHODS}

\section{Patient Selection and Treatment Details}

This retrospective study collected data from $121 \mathrm{mCSPC}$ patients treated at Odette Cancer Centre (Toronto, ON, Canada) between December 2014 and March 2021. Patient and treatment characteristics were extracted from SunnyCare (in-house electronic health information system). Eligible patients had mCSPC based on computed tomography (CT), bone scan, or both, and had to be on treatment with ADT with documented castrate testosterone $(\leq 1.7 \mathrm{nmol} / \mathrm{L})$.

DOC or ABI were prescribed at the discretion of the treating oncologist. DOC became provincially available for $\mathrm{MCSPC}$ in the second half of 2014, whereas ABI was approved by Health Canada in February 2018 and was made available via access program shortly thereafter for men with de novo high-risk mCSPC as per LATITUDE criteria.

The DOC regimen consisted of $75 \mathrm{mg} / \mathrm{m}^{2}$, initiated without prednisone, every 3 weeks for a maximum of six cycles. Patients were clinically assessed before each cycle of chemotherapy. Similarly, hematologic, hepatic, and renal functions as well as PSA were measured at baseline and before each cycle of chemotherapy. Thereafter, patients were usually evaluated every 3 months until progression of disease. Aside from baseline imaging, patients underwent repeat imaging at completion of DOC and every 6-12 months thereafter, or earlier as clinically indicated.

ABI was given at a dose of 1,000 mg once daily (without food), combined with prednisone $5 \mathrm{mg}$ once daily, and continued until either progression of disease or intolerance, whichever occurred first. Mostly, patients were assessed monthly for the first three months, and three-monthly thereafter. Routine bloodwork (including liver profile, creatinine, electrolytes, and PSA) was obtained biweekly for the first three months, and then every three months. Bone and CT scans were done at the treating physician's discretion, typically $\leq 12$ months after start of ABI and six-monthly thereafter. 
All study activities were approved by the Research Ethics Board of Sunnybrook Research Institute (Toronto, ON, Canada).

\section{Endpoints}

The predefined primary endpoint was progression free survival (PFS), defined as the interval from start of ADT to either (i) biochemical (applying the PCWG3 criteria (31)), radiological, or symptomatic progression, (ii) start of first-line systemic therapy for castration-resistant prostate cancer (CRPC), or (iii) death, whichever occurred first. Patients without progression event were censored at the last follow-up date or the data cutoff on March 15, 2021. Key secondary endpoints were OS, time to castration resistant prostate cancer (CRPC), and time to start of first line of systemic therapy for CRPC, all of those calculated from the start of ADT to the event of interest. PSA dynamics were also assessed as secondary endpoints, including the PSA nadir $\leq 0.2 \mathrm{ng} / \mathrm{mL}$ rate at 6 months as well as PSA50 and PSA90 response rates at 3 and 6 months.

\section{Statistical Analysis}

Patient and treatment characteristics of the DOC and ABI cohorts were compared using the Wilcoxon rank-sum nonparametric test for continuous variables or the Fisher exact test for categorical variables. PFS, OS, time to CRPC, and time to start of first line systemic therapy for CRPC were estimated by the Kaplan-Meier method, with log-rank test to compare the DOC versus ABI cohorts.

To search for predictive factors of PFS in the total population ( $\mathrm{n}=121$ ), we applied univariate and multivariable (i.e., backward stepwise selection procedure) Cox proportional hazard models, the latter adjusted for age and the Charlson Comorbidity Index (CCI). Hazard ratios (HRs) and 95\% confidence intervals (CIs) were calculated for each covariate. Natural log transformation was used for some variables to normalize the distribution. The generalized $\mathrm{R}^{2}$ was calculated based on the likelihood ratio statistic (LRT) for testing the global null hypothesis (32), using the formula of

$$
R^{2}=1-e^{-(L R T / n)}
$$

where $\operatorname{LRT}=-2 \log \mathrm{L}(0)-[-2 \log \mathrm{L}(\mathrm{p})], \mathrm{n}=$ sample size used, $\log \mathrm{L}(0)=\log$-likelihood for a null model with no covariates, and $\log \mathrm{L}(\mathrm{p})=\log$-likelihood for the fitted model with $\mathrm{p}$ covariates. $\mathrm{R}^{2}$ (between 0 and 1) is larger when the covariates are more strongly associated with the dependent variable.

Two-sided p-values $<0.05$ were considered statistically significant. Missing data was handled as real missing values, i.e., the complete data set was used since missing data was marginal $(<5 \%)$. All analyses were conducted using Statistical Analysis Software (SAS version 9.4, Cary, NC) and R package (v3.6.1).

\section{RESULTS}

\section{Patient and Treatment Characteristics}

A total of 121 patients met the eligibility criteria, of which 79 were treated with DOC and 42 received ABI. Patient characteristics
TABLE 1 | Patient and treatment characteristics.

\begin{tabular}{|c|c|c|c|}
\hline & $\begin{array}{l}\text { Abiraterone } \\
\qquad(\mathrm{N}=42)\end{array}$ & $\begin{array}{l}\text { Docetaxel } \\
(\mathbf{N}=79)\end{array}$ & $\begin{array}{c}\text { p- } \\
\text { value }\end{array}$ \\
\hline \multicolumn{4}{|l|}{ Demographics } \\
\hline Age at diagnosis of & & & $<.0001$ \\
\hline \multicolumn{4}{|l|}{ mCSPC (years) } \\
\hline Mean \pm SD & $72.40 \pm 7.92$ & $65.76 \pm 8.25$ & \\
\hline Median (Inter-quartiles) & $73.5(68.0,79.0)$ & $66.0(60.0,71.0)$ & \\
\hline Min, Max & $50.0,85.0$ & $44.0,90.0$ & \\
\hline Initial stage & & & 0.5536 \\
\hline Localized & $17(40.48 \%)$ & 27 (34.18\%) & \\
\hline Metastatic & 25 (59.52\%) & $52(65.82 \%)$ & \\
\hline Gleason score & & & 0.7240 \\
\hline 6 & 3 (7.89\%) & $4(5.56 \%)$ & \\
\hline 7 & $6(15.79 \%)$ & $15(20.83 \%)$ & \\
\hline $8-10$ & $29(76.32 \%)$ & $53(73.61 \%)$ & \\
\hline Local treatment & & & 0.4226 \\
\hline No & 25 (59.52\%) & $54(68.35 \%)$ & \\
\hline Yes & 17 (40.48\%) & 25 (31.65\%) & \\
\hline Prior neo/adjuvant ADT & & & 0.6212 \\
\hline No & 33 (78.57\%) & 66 (83.54\%) & \\
\hline Yes & $9(21.43 \%)$ & $13(16.46 \%)$ & \\
\hline Bone metastases & & & 0.2554 \\
\hline No & $3(7.14 \%)$ & 12 (15.19\%) & \\
\hline Yes & $39(92.86 \%)$ & 67 (84.81\%) & \\
\hline Lymph nodes metastases & & & 0.9597 \\
\hline No & 20 (47.62\%) & $38(48.10 \%)$ & \\
\hline Yes & $22(52.38 \%)$ & $41(51.90 \%)$ & \\
\hline Visceral metastases & & & 0.6493 \\
\hline No & 32 (76.19\%) & $63(79.75 \%)$ & \\
\hline Yes & $10(23.81 \%)$ & $16(20.25 \%)$ & \\
\hline CHAARTED criteria & & & 0.0866 \\
\hline Low volume & 7 (16.67\%) & 25 (31.65\%) & \\
\hline High volume & 35 (83.33\%) & $54(68.35 \%)$ & \\
\hline LATITUDE criteria & & & 0.1420 \\
\hline Low risk & $9(23.68 \%)$ & $30(39.47 \%)$ & \\
\hline High risk & $29(76.32 \%)$ & $46(60.53 \%)$ & \\
\hline Charlson Comorbidity & & & $<.0001$ \\
\hline \multicolumn{4}{|l|}{ Index } \\
\hline Mean \pm SD & $9.55 \pm 1.58$ & $8.52 \pm 1.10$ & \\
\hline Median (Inter-quartiles) & $9.0(9.0,10.0)$ & $9.0(8.0,9.0)$ & \\
\hline Min, Max & $7.0,16.0$ & $6.0,13.0$ & \\
\hline $\begin{array}{l}\text { PSA at start of ADT for } \\
\text { mCSPC }\end{array}$ & & & 0.4791 \\
\hline Mean \pm SD & $308.455 \pm 797.506$ & $280.985 \pm 718.502$ & \\
\hline Median (Inter-quartiles) & $\begin{array}{c}33.73(7.24 \\
107.00)\end{array}$ & $\begin{array}{c}32.63(11.68 \\
231.00)\end{array}$ & \\
\hline Min, Max & $1.78,3761.00$ & $0.13,5000.00$ & \\
\hline \multicolumn{4}{|l|}{ Treatment information } \\
\hline No. of cycles of DOC & & & NA \\
\hline $1-5$ & NA & 5 (6.33\%) & \\
\hline 6 & & $74(93.67 \%)$ & \\
\hline $\begin{array}{l}\text { Days from start of ADT to } \\
\text { start of } A B I / D O C\end{array}$ & & & 0.7604 \\
\hline Mean \pm SD & $63.12 \pm 39.47$ & $66.32 \pm 62.12$ & \\
\hline Median (Inter-quartiles) & $52.0(35.0,98.0)$ & $48.0(37.0,71.0)$ & \\
\hline Min, Max & $2.0,162.0$ & $18.0,437.0$ & \\
\hline $\begin{array}{l}\text { Reason for treatment } \\
\text { discontinuation }\end{array}$ & & & 0.0119 \\
\hline Disease progression & $6(14.29 \%)$ & $1(1.27 \%)$ & \\
\hline Toxicity/adverse event & $2(4.76 \%)$ & $4(5.06 \%)$ & \\
\hline Not applicable & 34 (80.95\%) & 74 (93.67\%) & \\
\hline
\end{tabular}

$A B I$, abiraterone; $A D T$, androgen deprivation therapy; DOC, docetaxel; mCSPC, metastatic castration-sensitive prostate cancer; PSA, prostate specific antigen. 
are detailed in Table 1. While the patient cohorts were comparable overall, DOC patients were younger [mean age \pm standard deviation (SD) $65.76 \pm 8.25$ versus $72.40 \pm 7.92$ years] and had a lower CCI (mean \pm SD $8.52 \pm 1.10$ versus $9.55 \pm 1.58$ ).

The median time from the start of ADT to initiation of either DOC or ABI was similar (48 days [interquartile range (IQR) 37,71] versus 52 days $(35,98) ; \mathrm{p}=0.76)$. The majority of chemotherapy patients completed six cycles of DOC (74/79, 93.67\%). Side effects accounted for DOC or ABI discontinuation in around $5 \%$ of patients each.

\section{PSA-Based Outcome Parameters}

The median PSA values at start of ADT were similar between both cohorts, $32.63 \mathrm{ng} / \mathrm{ml}$ (IQR 11.68,231.00) in patients treated with DOC and $33.73 \mathrm{ng} / \mathrm{ml}(7.24,107.00)$ in the ABI cohort (Table 1). While the majority of patients in both cohorts achieved a PSA decrease to well below $1 \mathrm{ng} / \mathrm{ml}$, PSA nadirbased parameters favored ABI patients. On the other hand, there were no statistically significant differences between the two groups in terms of PSA50 and PSA90 response rates (Table 2).

\section{Progression Free Survival}

After a median follow-up of 39.6 (IQR 26.9,47.2) and 25.1 (IQR $17.5,30.9)$ months in the DOC and ABI cohorts, respectively, $79.7 \%$ of men in the DOC and $40.5 \%$ in the $\mathrm{ABI}$ group experienced a progression event (Figure 1). PFS was triggered by biochemical progression in $71 \%$ of patients in the DOC group and in $80 \%$ of men in the ABI group. The remaining events were triggered by radiological changes. The actuarial median PFS was 18.5 months (95\%CI 12.6-23.7) in the DOC cohort, and 32.0 months (95\%CI 23.1-48.7) in the ABI cohort. While neither the median PSA nor the median radiological PFS was reached in men undergoing ABI therapy, the according medians were 24.2 and 26.8 months in the DOC group. Overall, the PFS analysis favored ABI $(\mathrm{p}=0.0038)$.

\section{Predictive Factors of Progression Free Survival}

Univariate analysis of the entire study cohort (Table 3) identified six factors significantly related to PFS. Older age at diagnosis of $\mathrm{mCSPC}$ $(\mathrm{HR}=0.969)$, PSA90 at 3 months $(\mathrm{HR}=0.472)$, and PSA nadir $\leq 0.2$ at 6 months $(\mathrm{HR}=0.524)$ translated to better outcome, whereas PFS was shorter in men with high-risk disease features according to the LATITUDE criteria $(\mathrm{HR}=1.653)$, high-volume disease as per CHAARTED criteria $(\mathrm{HR}=1.722)$, and de novo metastatic disease $(\mathrm{HR}=1.737)$. To account for significant differences regarding age and comorbidities in the ABI versus DOC cohorts (Table 1), the final multivariable model (Table 4) was adjusted for age and CCI. It revealed three factors that remained significant: age at diagnosis of mCSPC $(\mathrm{HR}=0.955)$, PSA90 at 3 months $(\mathrm{HR}=$ 0.462), and the LATITUDE risk classification $(\mathrm{HR}=1.965)$.

\section{Secondary Endpoints}

While the actuarial median OS was not reached in the ABI cohort, it was 57.5 months (95\%CI 40.5-62.5) in the DOC group $(\mathrm{p}=0.97)$. OS at 12 months was $98.7 \%$ (95\%CI 96.3-100\%) and $92.7 \%(85.0-100 \%)$ in the DOC and ABI groups, respectively

(Figure 2). In terms of time to CRPC, there was a statistically
TABLE 2 | PSA-based outcome parameters.

\begin{tabular}{|c|c|c|c|}
\hline & $\begin{array}{l}\text { Abiraterone } \\
\qquad(\mathrm{N}=42)\end{array}$ & $\begin{array}{l}\text { Docetaxel } \\
(\mathbf{N}=79)\end{array}$ & $\begin{array}{c}\text { p- } \\
\text { value }\end{array}$ \\
\hline PSA nadir & & & 0.0007 \\
\hline $\mathrm{N}$ & 26 & 75 & \\
\hline Mean \pm SD & $0.469 \pm 1.801$ & $2.108 \pm 4.609$ & \\
\hline Median (Inter-quartiles) & $0.02(0.02,0.09)$ & $0.20(0.02,1.35)$ & \\
\hline Min, Max & $0.02,9.20$ & $0.02,24.59$ & \\
\hline PSA nadir categories & & & 0.0061 \\
\hline$<0.2$ & $22(84.62 \%)$ & 37 (49.33\%) & \\
\hline $0.2-4.0$ & $3(11.54 \%)$ & $26(34.67 \%)$ & \\
\hline$>4.0$ & $1(3.85 \%)$ & $12(16.00 \%)$ & \\
\hline PSA nadir $\leq 0.2$ at 6 months & & & 0.0155 \\
\hline No & $15(57.69 \%)$ & $62(82.67 \%)$ & \\
\hline Yes & $11(42.31 \%)$ & $13(17.33 \%)$ & \\
\hline $\begin{array}{l}\text { Days from start of ADT to PSA } \\
\text { nadir }\end{array}$ & & & 0.5733 \\
\hline Mean \pm SD & $232.88 \pm 152.05$ & $225.91 \pm 104.73$ & \\
\hline Median (Inter-quartiles) & $\begin{array}{c}172.5(128.0 \\
338.0)\end{array}$ & $\begin{array}{c}204.0(154.0 \\
299.0)\end{array}$ & \\
\hline Min, Max & $83.0,736.0$ & $35.0,497.0$ & \\
\hline $\begin{array}{l}\text { PSA at } 3 \text { months from start of } \\
\text { ADT }\end{array}$ & & & 0.1985 \\
\hline $\mathrm{N}$ & 41 & 77 & \\
\hline Mean \pm SD & $14.784 \pm 46.321$ & $6.963 \pm 13.217$ & \\
\hline Median (Inter-quartiles) & $0.27(0.10,3.03)$ & $0.91(0.20,6.59)$ & \\
\hline Min, Max & $0.02,259.70$ & $0.02,61.98$ & \\
\hline $\begin{array}{l}\text { PSA at } 6 \text { months from start of } \\
\text { ADT }\end{array}$ & & & 0.3240 \\
\hline$N$ & 39 & 73 & \\
\hline Mean $\pm \mathrm{SD}$ & $6.492 \pm 17.505$ & $3.867 \pm 9.826$ & \\
\hline Median (Inter-quartiles) & $0.20(0.03,1.00)$ & $0.30(0.05,2.49)$ & \\
\hline Min, Max & $0.02,74.93$ & $0.02,69.69$ & \\
\hline $\begin{array}{l}\text { PSA50 at } 3 \text { months from start } \\
\text { of ADT }\end{array}$ & & & 0.3400 \\
\hline No & 3 (7.32\%) & 2 (2.60\%) & \\
\hline Yes & 38 (92.68\%) & 75 (97.40\%) & \\
\hline $\begin{array}{l}\text { PSA90 at } 3 \text { months from start } \\
\text { of ADT }\end{array}$ & & & 0.6339 \\
\hline No & $7(17.07 \%)$ & 17 (22.08\%) & \\
\hline Yes & 34 (82.93\%) & 60 (77.92\%) & \\
\hline $\begin{array}{l}\text { PSA50 at } 6 \text { months from start } \\
\text { of ADT }\end{array}$ & & & 0.2774 \\
\hline No & $2(5.13 \%)$ & 1 (1.37\%) & \\
\hline Yes & 37 (94.87\%) & 72 (98.63\%) & \\
\hline $\begin{array}{l}\text { PSA90 at } 6 \text { months from start } \\
\text { of ADT }\end{array}$ & & & 0.4419 \\
\hline No & 5 (12.82\%) & 14 (19.18\%) & \\
\hline Yes & 34 (87.18\%) & 59 (80.82\%) & \\
\hline
\end{tabular}

$A D T$, androgen deprivation therapy; PSA, prostate specific antigen.

significant difference between the treatment cohorts $(\mathrm{p}<0.0001)$; the actuarial median time to CRPC was 18.6 months $(95 \% \mathrm{CI}$ 12.6-25.1) in the DOC group and not reached in the ABI group (Figure 3). The actuarial median time to first line therapy for CRPC was 20.6 months (95\%CI, 14.6-28.1) in the DOC group and not reached in patients who received $A B I$, statistically favoring $\mathrm{ABI}(\mathrm{p}=0.0086)$.

\section{DISCUSSION}

In our retrospective single-center cohort study, we found mCSPC patients treated with DOC to be younger, having less 


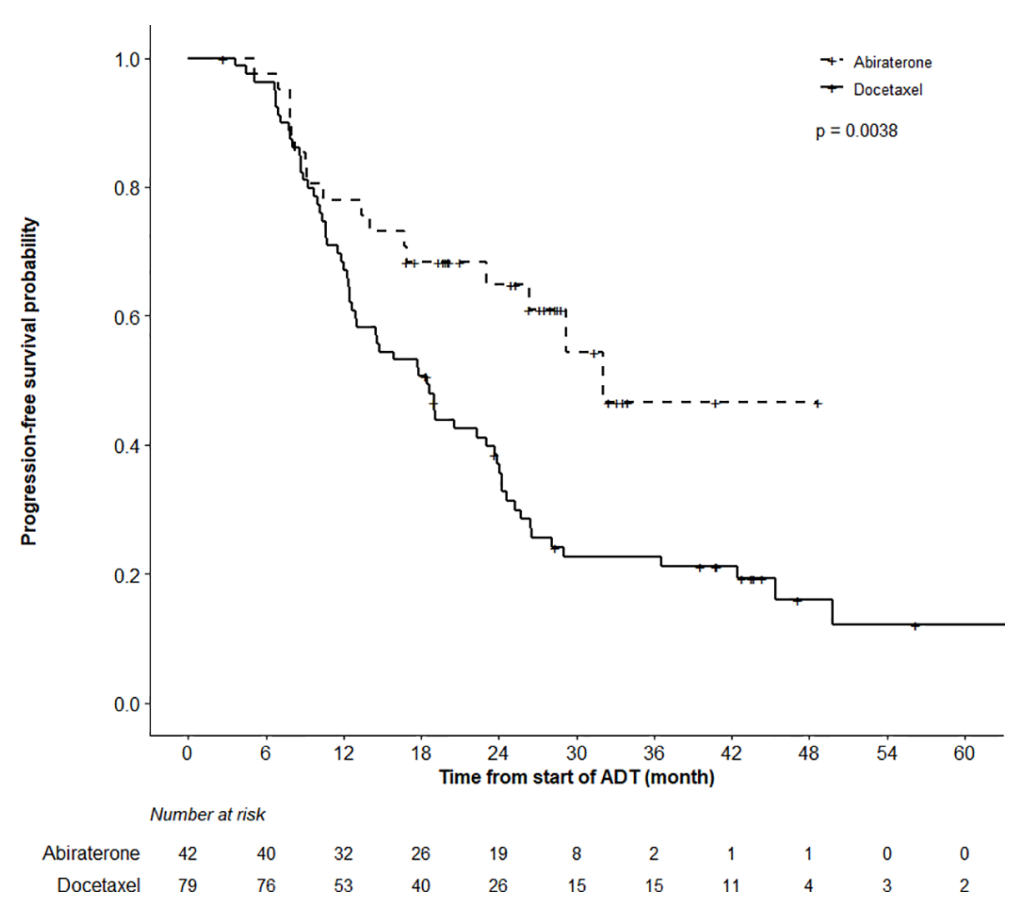

FIGURE 1 | Progression Free Survival (PFS) Analysis. PFS analysis in patients undergoing abiraterone versus docetaxel therapy until month 48 revealed superior outcome in abiraterone patients (log-rank test, $p=0.0038$ ).

TABLE 3 | Predictive factors of progression-free survival: univariate analysis.

\begin{tabular}{|c|c|c|c|c|c|}
\hline \multirow{2}{*}{$\begin{array}{l}\text { Predictive factors } \\
\text { Age at diagnosis of mCSPC (years) }\end{array}$} & \multirow{2}{*}{$\begin{array}{c}\text { P-value } \\
0.0246\end{array}$} & \multirow{2}{*}{$\begin{array}{c}\text { HR } \\
0.969\end{array}$} & \multicolumn{2}{|c|}{$95 \% \mathrm{Cl}$ of $\mathrm{HR}$} & \multirow{2}{*}{$\begin{array}{r}R^{2}(\%) \\
4.06\end{array}$} \\
\hline & & & 0.942 & 0.996 & \\
\hline Initial stage (metastatic vs. localized) & 0.0256 & 1.737 & 1.070 & 2.822 & 4.32 \\
\hline Gleason score $\geq 8$ (yes vs. no) & 0.1843 & 1.477 & 0.831 & 2.625 & 1.71 \\
\hline Visceral metastasis (yes vs. no) & 0.5068 & 0.826 & 0.470 & 1.452 & 0.38 \\
\hline CHAARTED criteria (high vs. low volume) & 0.0439 & 1.722 & 1.015 & 2.923 & 3.61 \\
\hline LATITUDE criteria (high vs. low risk) & 0.0496 & 1.653 & 1.001 & 2.729 & 3.53 \\
\hline Charlson Comorbidity Index $\geq 9$ (yes vs. no) & 0.6846 & 0.912 & 0.586 & 1.421 & 0.14 \\
\hline Days from start of ADT to start of $\mathrm{ABI}$ or DOC (log) & 0.7822 & 1.046 & 0.759 & 1.443 & 0.06 \\
\hline PSA at start of ADT (log) & 0.3670 & 1.049 & 0.946 & 1.164 & 0.67 \\
\hline PSA50 at 3 months from start of ADT (yes vs. no) & 0.2914 & 0.579 & 0.209 & 1.599 & 0.81 \\
\hline PSA90 at 3 months from start of ADT (yes vs. no) & 0.0037 & 0.472 & 0.285 & 0.784 & 6.13 \\
\hline PSA nadir $\leq 0.2$ at 6 months (yes vs. no) & 0.0437 & 0.524 & 0.280 & 0.982 & 4.50 \\
\hline
\end{tabular}

ABI, abiraterone; ADT, androgen deprivation therapy; DOC, docetaxel; mCSPC, metastatic castration-sensitive prostate cancer; PSA, prostate specific antigen.

TABLE 4 | Predictive factors of progression-free survival: multivariable analysis, adjusted for age and Charlson Comorbidity Index.

\begin{tabular}{|c|c|c|c|c|c|}
\hline \multirow{2}{*}{$\begin{array}{l}\text { Multivariable Model } \\
\text { Age at diagnosis of mCSPC (years) }\end{array}$} & \multirow{2}{*}{$\begin{array}{l}\text { P-value } \\
0.0253\end{array}$} & \multirow{2}{*}{$\begin{array}{c}\text { HR } \\
0.955\end{array}$} & \multicolumn{2}{|c|}{$95 \% \mathrm{Cl}$ of $\mathrm{HR}$} & \multirow{2}{*}{$\frac{R^{2}(\%)}{15.80}$} \\
\hline & & & 0.918 & 0.994 & \\
\hline Charlson Comorbidity Index $\geq 9$ (yes vs. no) & 0.1066 & 1.679 & 0.895 & 3.150 & \\
\hline LATITUDE criteria (high vs. low risk) & 0.0116 & 1.965 & 1.163 & 3.320 & \\
\hline PSA90 at 3 months from start of ADT (yes vs. no) & 0.0050 & 0.462 & 0.270 & 0.792 & \\
\hline
\end{tabular}

$A D T$, androgen deprivation therapy; MCSPC, metastatic castration-sensitive prostate cancer; PSA, prostate specific antigen.

comorbidities, and experiencing shorter PFS compared to men undergoing ABI therapy. Similarly, the time to first line systemic therapy for CRPC was shorter in the DOC group. Since PFS and the diagnosis of CRPC were triggered by biochemical progression in the majority of patients, it is not unexpected that these outcome measures were favored by $\mathrm{ABI}$ over $\mathrm{DOC}$, owing to the androgen synthesis inhibitory activity of $\mathrm{ABI}$. However, there was no significant difference in OS between the two treatment modalities. As such our population-based results confirm the findings of the opportunistic comparison between 


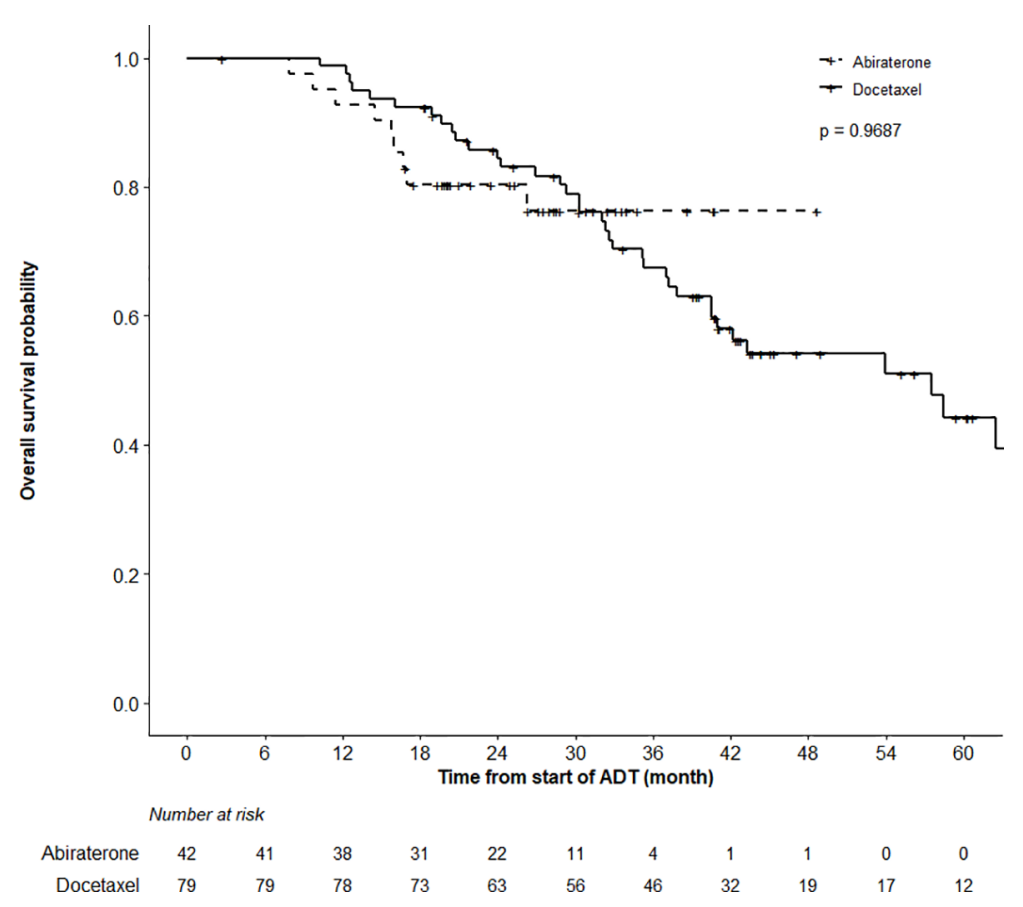

FIGURE 2 | Overall Survival (OS) Analysis. Comparing OS in patients treated with abiraterone versus docetaxel using the log-rank test did not find a significant OS difference between groups $(p=0.9687)$. Patients alive or lost-to-follow-up were censored.

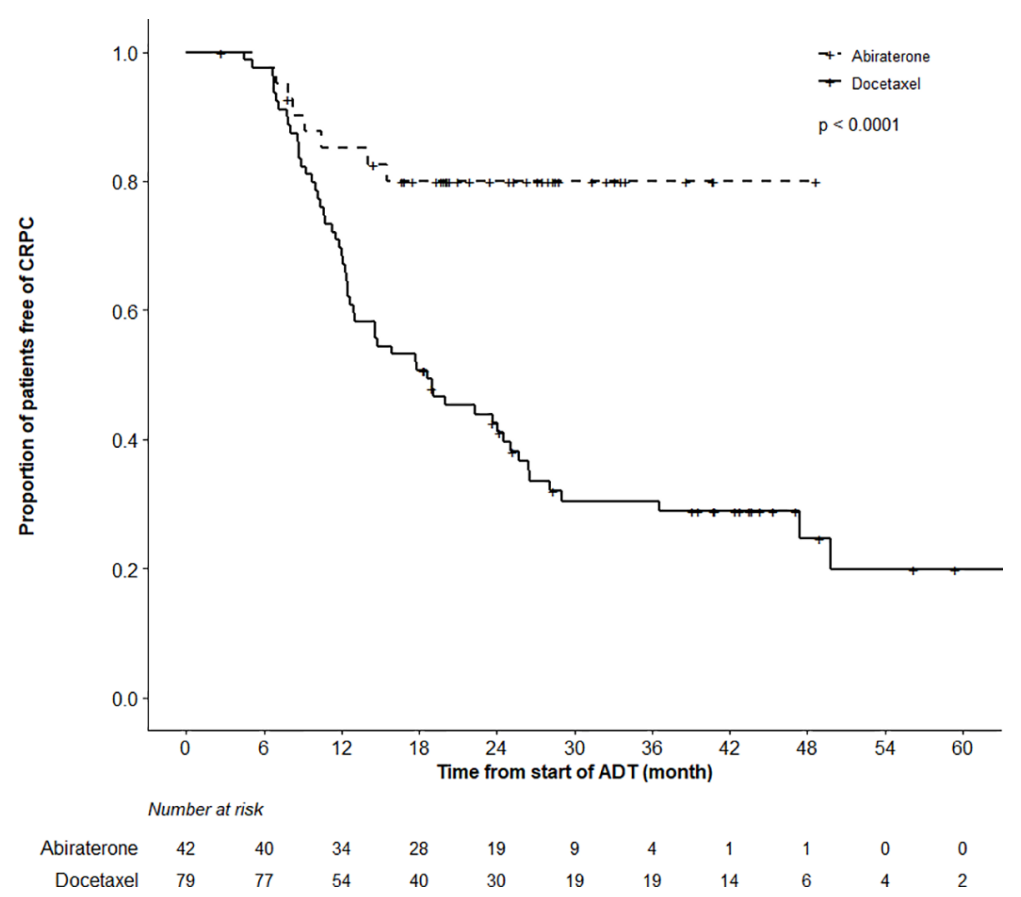

FIGURE 3 | Time to Castration-Resistant Prostate Cancer (CRPC) Analysis. There was a highly significant difference in the time to CRPC between the abiraterone and docetaxel treatment groups (log-rank test, $p<0.0001$ ). 
the DOC and ABI arms of the STAMPEDE trial (arms C and G, respectively) (17).

Our study also documents the feasibility and effectiveness of both DOC and ABI under real-world conditions. In fact, 93.7\% of our patients completed six cycles of DOC, and only approximately $5 \%$ of patients stopped either DOC or ABI because of adverse effects. With respect to DOC effectiveness, our DOC cohort was comparable to the CHAARTED population of men undergoing chemohormonal therapy regarding median age (65.76 versus 64 years) and rate of high volume disease (68.35 versus $66.2 \%$ ), de novo metastatic presentation (65.82 versus $72.8 \%$ ), visceral metastasis (20.25 versus $14.4 \%$ ), and Gleason score 7 or higher disease (94.4 versus 94.1\%) (24). The median OS was 57.6 months in CHAARTED and 57.5 months in our group of patients after a median follow-up of 39.6 months. Furthermore, the median time to CRPC was 18.6 (95\%CI 12.6-25.1) and $20.2(17.2-23.6)$ months in our cohort versus the experimental arm of CHAARTED, respectively (24). On the contrary, Lavoie et al. described inferior outcomes in their population-based series of 156 patients compared to our findings (33). However, their rate of high-volume disease was higher (79.5 versus $68.35 \%$ ); fewer patients finished six cycles of DOC (81 versus 93.7\%), and more men discontinued DOC because of toxicities (10 versus $5 \%$ ).

With respect to $\mathrm{ABI}$, our cohort was older compared to LATITUDE AND STAMPEDE-G, and situated between these two clinical trial populations in terms of risk factors such as LATITUDE high-risk and CHAARTED high-volume disease, de novo presentation, and rate of visceral metastasis. Although the relatively short median follow-up of 25.1 months of our patients precludes a definite comparison with LATITUDE and STAMPEDE-G, it is reassuring that $80.4 \%$ of our patients were alive at 2 years.

For the identification of predictive factors of clinical benefit, we focused on PFS as the primary endpoint in the entire study cohort. LATITUDE low-risk disease, achieving a PSA90 at 3 months, and older age at diagnosis of $\mathrm{MCSPC}$ were found to be independently associated with longer PFS. Interestingly, CHAARTED low-volume disease at baseline did not result in prolonged PFS in multivariable analysis. The LATITUDE risk definition might have better predictive potential because it incorporates not only tumor burden but also de novo presentation as factors of worse outcome (34). Deep PSA responses have been associated with superior outcome in men undergoing chemohormonal therapy or ABI combined with ADT for mCSPC $(28,30)$. Similarly, in our cohort PSA90 at 3 months was an independent predictor of superior PFS. With longer follow-up, we will be able to use our dataset for a predictive factor analysis using OS as the primary endpoint.

In the future, predictive clinical parameters such as the ones identified in our analysis might be used in conjunction with emerging molecular markers for therapeutic decisions. SPOP mutations appear to identify a group of mCPSC patients with excellent response to ADT alone (35). Conversely, Harshman et al. showed that elevated IL-8 levels predict shorter time to CRPC and OS independent of DOC administration, tumor burden, and recurrent versus de novo metastatic presentation, using baseline serum samples from CHAARTED (36). Luminal B subtype $\mathrm{mCSPC}$ was found to be associated with superior OS in men undergoing chemohormonal therapy compared to ADT alone, whereas men with basal subtype did not benefit from adding DOC (37). Combining ADT with apalutamide (and potentially other ARSIs) might be particularly needed in mCSPC with a high DECIPHER ${ }^{\circledR}$ genomic classifier score, low androgen receptor activity, and/or basal phenotype (38). The presence of germline DNA damage repair alterations predicts early progression from de novo mCSPC to mCRPC, yet such patients might be amenable to treatment with poly (ADP-ribose) polymerase inhibitors (39). Finally, deep tumor sequencing is expected to aid further in the precise molecular classification of mCSPC for therapeutic decision making (40-42).

Some limitations regarding our analyses are worth mentioning, including the retrospective data collection and limited sample size. Furthermore, the single institution nature of our study could affect the external validation of our findings, as could differences between the treatment cohorts in terms of age, comorbidities and time of follow-up among others. Regarding the latter, the relatively short median follow-up in the $\mathrm{ABI}$ arm is explained by the only recent availability in Canada of ABI for mCSPC. Furthermore, imaging was timed according to treating physicians' discretion, which could impact the assessment of PFS.

To sum up, the findings presented herein support the feasibility and effectiveness of combining DOC or ABI with ADT for men with mCSPC under real-world conditions. The presence of high-risk MCSPC as per LATITUDE criteria, lack of a PSA90 at 3 months, and younger age at diagnosis of mCPSC predict shorter PFS and as such may identify a cohort of patients in need for further refinement of the initial management.

\section{DATA AVAILABILITY STATEMENT}

The raw, de-identification data supporting the conclusions of this article will be made available by the authors without undue reservation.

\section{ETHICS STATEMENT}

The studies involving human participants were reviewed and approved by the Research Ethics Board of Sunnybrook Research Institute. Written informed consent for participation was not required for this study in accordance with the national legislation and the institutional requirements.

\section{AUTHOR CONTRIBUTIONS}

JB and UE conceived and designed the study. JB, MK, and AS collected and assembled the data. LZ performed 
the statistical analysis. JB, MS, and UE analyzed and interpreted the data. JB and UE wrote the manuscript. All authors contributed to the article and approved the submitted version.

\section{REFERENCES}

1. Teoh JYC, Hirai HW, Ho JMW, Chan FCH, Tsoi KKF, Ng CF. Global Incidence of Prostate Cancer in Developing and Developed Countries With Changing Age Structures. PloS One (2019) 14(10):e0221775. doi: 10.1371/ journal.pone.0221775

2. Bernard B, Muralidhar V, Chen Y-H, Sridhar SS, Mitchell EP, Pettaway CA, et al. Impact of Ethnicity on the Outcome of Men With Metastatic, HormoneSensitive Prostate Cancer. Cancer (2017) 123(9):1536-44. doi: 10.1002/ cncr.30503

3. Artibani W, Porcaro AB, De Marco V, Cerruto MA, Siracusano S. Management of Biochemical Recurrence After Primary Curative Treatment for Prostate Cancer: A Review. Urol Int (2018) 100(3):251-62. doi: 10.1159/ 000481438

4. Fizazi K, Tran N, Fein L, Matsubara N, Rodriguez-Antolin A, Alekseev BY, et al. Abiraterone Plus Prednisone in Metastatic, Castration-Sensitive Prostate Cancer. New Engl J Med (2017) 377(4):352-60. doi: 10.1056/NEJMoa1704174

5. James ND, de Bono JS, Spears MR, Clarke NW, Mason MD, Dearnaley DP, et al. Abiraterone for Prostate Cancer Not Previously Treated With Hormone Therapy. New Engl J Med (2017) 377(4):338-51. doi: 10.1056/ NEJMoa1702900

6. Armstrong AJ, Szmulewitz RZ, Petrylak DP, Holzbeierlein J, Villers A, Azad A, et al. Arches: A Randomized, Phase Iii Study of Androgen Deprivation Therapy With Enzalutamide or Placebo in Men With Metastatic HormoneSensitive Prostate Cancer. J Clin Oncol (2019) 37(32):2974-86. doi: 10.1200/ JCO.19.00799

7. Davis ID, Martin AJ, Stockler MR, Begbie S, Chi KN, Chowdhury S, et al. Enzalutamide With Standard First-Line Therapy in Metastatic Prostate Cancer. New Engl J Med (2019) 381(2):121-31. doi: 10.1056/NEJMoa1903835

8. Chi KN, Agarwal N, Bjartell A, Chung BH, Pereira de Santana Gomes AJ, Given R, et al. Apalutamide for Metastatic, Castration-Sensitive Prostate Cancer. N Engl J Med (2019) 381(1):13-24. doi: 10.1056/NEJMoa1903307

9. Kyriakopoulos CE, Chen Y-H, Carducci MA, Liu G, Jarrard DF, Hahn NM, et al. Chemohormonal Therapy in Metastatic Hormone-Sensitive Prostate Cancer: Long-Term Survival Analysis of the Randomized Phase III E3805 CHAARTED Trial. J Clin Oncol (2018) 36(11):1080-7. doi: 10.1200/ JCO.2017.75.3657

10. James ND, Sydes MR, Clarke NW, Mason MD, Dearnaley DP, Spears MR, et al. Addition of Docetaxel, Zoledronic Acid, or Both to First-Line LongTerm Hormone Therapy in Prostate Cancer (STAMPEDE): Survival Results From an Adaptive, Multiarm, Multistage, Platform Randomised Controlled Trial. Lancet (2016) 387(10024):1163-77. doi: 10.1016/S0140-6736(15) 01037-5

11. Gravis G, Boher JM, Joly F, Soulié M, Albiges L, Priou F, et al. Androgen Deprivation Therapy (Adt) Plus Docetaxel Versus Adt Alone in Metastatic non Castrate Prostate Cancer: Impact of Metastatic Burden and Long-term Survival Analysis of the Randomized Phase 3 GETUG-AFU15 Trial. Eur Urol (2016) 70(2):256-62. doi: 10.1016/j.eururo.2015.11.005

12. Parker CC, James ND, Brawley CD, Clarke NW, Hoyle AP, Ali A, et al. Radiotherapy to the Primary Tumour for Newly Diagnosed, Metastatic Prostate Cancer (STAMPEDE): A Randomised Controlled Phase 3 Trial. Lancet (2018) 392(10162):2353-66. doi: 10.1016/S01406736(18)32486-3

13. Boevé LMS, Hulshof M, Vis AN, Zwinderman AH, Twisk JWR, Witjes WPJ, et al. Effect on Survival of Androgen Deprivation Therapy Alone Compared to Androgen Deprivation Therapy Combined With Concurrent Radiation Therapy to the Prostate in Patients With Primary Bone Metastatic Prostate Cancer in a Prospective Randomised Clinical Trial: Data From the HORRAD Trial. Eur Urol (2019) 75(3):410-8. doi: 10.1016/j.eururo. 2018.11.007

\section{FUNDING}

This study was made possible by support from the Joseph and Silvana Melara Cancer Research Fund (Toronto, ON, Canada) to UE.

14. Kwan EM, Thangasamy IA, Teh J, Alghazo O, Sathianathen NJ, Lawrentschuk N, et al. Navigating Systemic Therapy for Metastatic Castration-Naïve Prostate Cancer. World J Urol (2020). doi: 10.1007/s00345-019-03060-7

15. Hall ME, Huelster HL, Luckenbaugh AN, Laviana AA, Keegan KA, Klaassen Z, et al. Metastatic Hormone-sensitive Prostate Cancer: Current Perspective on the Evolving Therapeutic Landscape. Onco Targets Ther (2020) 13:357181. doi: 10.2147/OTT.S228355

16. Virgo KS, Rumble RB, de Wit R, Mendelson DS, Smith TJ, Taplin ME, et al. Initial Management of Noncastrate Advanced, Recurrent, or Metastatic Prostate Cancer: Asco Guideline Update. J Clin Oncol (2021) 39(11):1274305. doi: $10.1200 / J C O .20 .03256$

17. Sydes MR, Spears MR, Mason MD, Clarke NW, Dearnaley DP, de Bono JS, et al. Adding Abiraterone or Docetaxel to Long-Term Hormone Therapy for Prostate Cancer: Directly Randomised Data From the STAMPEDE MultiArm, Multi-Stage Platform Protocol. Ann Oncol (2018) 29(5):1235-48. doi: 10.1093/annonc/mdy072

18. Sathianathen NJ, Koschel S, Thangasamy IA, Teh J, Alghazo O, Butcher G, et al. Indirect Comparisons of Efficacy Between Combination Approaches in Metastatic Hormone-Sensitive Prostate Cancer: A Systematic Review and Network Meta-Analysis. Eur Urol (2020) 77(3):365-72. doi: 10.1016/ j.eururo.2019.09.004

19. Wallis CJD, Klaassen Z, Bhindi B, Goldberg H, Chandrasekar T, Farrell AM, et al. Comparison of Abiraterone Acetate and Docetaxel With Androgen Deprivation Therapy in High-risk and Metastatic Hormone-Naïve Prostate Cancer: A Systematic Review and Network Meta-Analysis. Eur Urol (2018) 73 (6):834-44. doi: 10.1016/j.eururo.2017.10.002

20. Aguiar PN Jr, Tan PS, Simko S, Barreto CMN, Gutierres BS, Giglio AD, et al. Cost-Effectiveness Analysis of Abiraterone, Docetaxel or Placebo Plus Androgen Deprivation Therapy for Hormone-Sensitive Advanced Prostate Cancer. Einstein (Sao Paulo) (2019) 17(2):eGS4414. doi: 10.31744/ einstein_journal/2019GS4414

21. Hird AE, Magee DE, Cheung DC, Matta R, Kulkarni GS, Nam RK Abiraterone vs. Docetaxel for Metastatic Hormone-Sensitive Prostate Cancer: A Microsimulation Model. Can Urol Assoc J (2020). doi: 10.5489/ cuaj.6234

22. Ramamurthy C, Handorf EA, Correa AF, Beck JR, Geynisman DM. CostEffectiveness of Abiraterone Versus Docetaxel in the Treatment of Metastatic Hormone Naïve Prostate Cancer. Urol Oncol (2019) 37(10):688-95. doi: 10.1016/j.urolonc.2019.05.017

23. Grivas PD, Robins DM, Hussain M. Predicting Response to Hormonal Therapy and Survival in Men With Hormone Sensitive Metastatic Prostate Cancer. Crit Rev Oncol/Hematol (2013) 85(1):82-93. doi: 10.1016/ j.critrevonc.2012.05.003

24. Sweeney CJ, Chen Y-H, Carducci M, Liu G, Jarrard DF, Eisenberger M, et al. Chemohormonal Therapy in Metastatic Hormone-Sensitive Prostate Cancer. New Engl J Med (2015) 373(8):737-46. doi: 10.1056/NEJMoa1503747

25. Hoyle AP, Ali A, James ND, Cook A, Parker CC, de Bono JS, et al. Abiraterone in "High-" and "Low-Risk" Metastatic Hormone-Sensitive Prostate Cancer. Eur Urol (2019) 76(6):719-28. doi: 10.1016/j.eururo.2019.08.006

26. Buelens S, Poelaert F, Dhondt B, Fonteyne V, De Visschere P, Ost P, et al. Metastatic Burden in Newly Diagnosed Hormone-Naive Metastatic Prostate Cancer: Comparing Definitions of CHAARTED and LATITUDE Trial. Urol Oncol (2018) 36(4):158.e13-158.e20. doi: 10.1016/j.urolonc.2017.12.009

27. Iacovelli R, Ciccarese C, Mosillo C, Bimbatti D, Fantinel E, Stefani L, et al. Comparison Between Prognostic Classifications in De Novo Metastatic Hormone Sensitive Prostate Cancer. Target Oncol (2018) 13(5):649-55. doi: 10.1007/s11523-018-0588-8

28. Harshman LC, Chen Y-H, Liu G, Carducci MA, Jarrard D, Dreicer R, et al. Seven-Month Prostate-Specific Antigen Is Prognostic in Metastatic HormoneSensitive Prostate Cancer Treated With Androgen Deprivation With or 
Without Docetaxel. J Clin Oncol (2018) 36(4):376-82. doi: 10.1200/ JCO.2017.75.3921

29. Tomioka A, Tanaka N, Yoshikawa M, Miyake M, Anai S, Chihara Y, et al. Nadir PSA Level and Time to Nadir PSA are Prognostic Factors in Patients With Metastatic Prostate Cancer. BMC Urol (2014) 14(1):33. doi: 10.1186/ 1471-2490-14-33

30. Matsubara N, Chi KN, Özgüroğlu M, Rodriguez-Antolin A, Feyerabend S, Fein L, et al. Correlation of Prostate-specific Antigen Kinetics With Overall Survival and Radiological Progression-Free Survival in Metastatic CastrationSensitive Prostate Cancer Treated With Abiraterone Acetate Plus Prednisone or Placebos Added to Androgen Deprivation Therapy: Post Hoc Analysis of Phase 3 LATITUDE Study. Eur Urol (2020) 77(4):494-500. doi: 10.1016/ j.eururo.2019.11.021

31. Scher HI, Morris MJ, Stadler WM, Higano C, Basch E, Fizazi K, et al. Trial Design and Objectives for Castration-Resistant Prostate Cancer: Updated Recommendations From the Prostate Cancer Clinical Trials Working Group 3. J Clin Oncol (2016) 34(12):1402-18. doi: 10.1200/JCO.2015. 64.2702

32. Paul D. Survival Analysis Using the SAS System: A Practical Guide. 2nd ed. Cary, NC: SAS Institute Inc (2010) p. 282-3.

33. Lavoie JM, Zou K, Khalaf D, Eigl BJ, Kollmannsberger CK, Vergidis J, et al. Clinical Effectiveness of Docetaxel for Castration-Sensitive Prostate Cancer in a Real-World Population-Based Analysis. Prostate (2019) 79(3):281-7. doi: 10.1002/pros.23733

34. Sharma AP, Mavuduru RS, Bora GS, Devana SK, Singh SK, Mandal AK. Stampedeing Metastatic Prostate Cancer: CHAARTing the Latitudes. Indian $J$ Urol (2018) 34(3):180-4. doi: 10.4103/iju.IJU_378_17

35. Swami U, Isaacsson Velho P, Nussenzveig R, Chipman J, Sacristan Santos V, Erickson S, et al. Association of SPOP Mutations With Outcomes in Men With De Novo Metastatic Castration-Sensitive Prostate Cancer. Eur Urol (2020) 78(5):652-6. doi: 10.1016/j.eururo.2020.06.033

36. Harshman LC, Wang VX, Hamid AA, Santone G, Drake CG, Carducci MA, et al. Impact of Baseline Serum IL-8 on Metastatic Hormone-Sensitive Prostate Cancer Outcomes in the Phase 3 CHAARTED Trial (E3805). Prostate (2020) 80(16):1429-37. doi: 10.1002/pros.24074

37. Hamid A, Wang XV, Chen Y-H, Feng FY, Den RB, Attard G, et al. Luminal B Subtype as a Predictive Biomarker of Docetaxel Benefit for Newly Diagnosed Metastatic Hormone Sensitive Prostate Cancer (Mhspc): A Correlative Study of E3805 Chaarted. J Clin Oncol (2020) 38(6_suppl):162-2. doi: 10.1200/ JCO.2020.38.6_suppl.162

38. Feng FY, Thomas S, Aguilar-Bonavides C, Gormley M, Agarwal N, Attard G, et al. Molecular Determinants of Outcome for Metastatic Castration-Sensitive Prostate Cancer (mCSPC) With Addition of Apalutamide (APA) or Placebo (PBO) to Androgen Deprivation Therapy (ADT) in TITAN. J Clin Oncol (2020) 38(15_suppl):5535-5. doi: 10.1200/JCO.2020.38.15_suppl.5535

39. Wei Y, Wu J, Gu W, Wang J, Lin G, Qin X, et al. Prognostic Value of Germline Dna Repair Gene Mutations in De Novo Metastatic and Castration-Sensitive Prostate Cancer. Oncologist (2020) 25(7):e1042-50. doi: 10.1634/ theoncologist.2019-0495

40. Stopsack KH, Nandakumar S, Wibmer AG, Haywood S, Weg ES, Barnett ES, et al. Oncogenic Genomic Alterations, Clinical Phenotypes, and Outcomes in Metastatic Castration-Sensitive Prostate Cancer. Clin Cancer Res (2020) 26 (13):3230-8. doi: 10.1158/1078-0432.CCR-20-0168

41. Abida W, Armenia J, Gopalan A, Brennan R, Walsh M, Barron D, et al. Prospective Genomic Profiling of Prostate Cancer Across Disease States Reveals Germline and Somatic Alterations That may Affect Clinical Decision Making. JCO Precis Oncol (2017) 2017. doi: 10.1200/PO.17.00029

42. Gilson C, Ingleby F, Gilbert DC, Parry MA, Atako NB, Ali A, et al. Genomic Profiles of De Novo High- and Low-Volume Metastatic Prostate Cancer: Results From a 2-Stage Feasibility and Prevalence Study in the STAMPEDE Trial. JCO Precis Oncol (2020) 4:882-97. doi: 10.1200/PO.19.00388

Conflict of Interest: UE has received honoraria from Janssen Inc. Canada for consulting and educational activities.

The remaining authors declare that the research was conducted in the absence of any commercial or financial relationships that could be construed as a potential conflict of interest.

Copyright $\odot 2021$ Briones, Khan, Sidhu, Zhang, Smoragiewicz and Emmenegger. This is an open-access article distributed under the terms of the Creative Commons Attribution License (CC BY). The use, distribution or reproduction in other forums is permitted, provided the original author(s) and the copyright owner(s) are credited and that the original publication in this journal is cited, in accordance with accepted academic practice. No use, distribution or reproduction is permitted which does not comply with these terms. 